\title{
An Outbreak of Strangles in Arabian Horses in Saudi Arabia: Epidemiology, Clinical Signs and Treatment Outcomes
}

\author{
Salama A. Osman ${ }^{1,2}$, Mohamed Tharwat ${ }^{1,3}$ and Elhassan M.A. Saeed ${ }^{1,4^{*}}$ \\ ${ }^{1}$ Department of Veterinary Medicine, College of Agriculture and Veterinary Medicine, Qassim University, P.O. Box 6622, \\ Buraidah, 51452, Saudi Arabia \\ ${ }^{2}$ Department of Animal Medicine, Faculty of Veterinary Medicine, Kafrelsheikh University, Egypt \\ ${ }^{3}$ Department of Animal Medicine, Faculty of Veterinary Medicine, Zagazig University, Egypt \\ ${ }^{4}$ Department of Microbiology, Faculty of Veterinary Medicine, University of Khartoum, Sudan \\ *Corresponding author: esaeed25@gmail.com
}

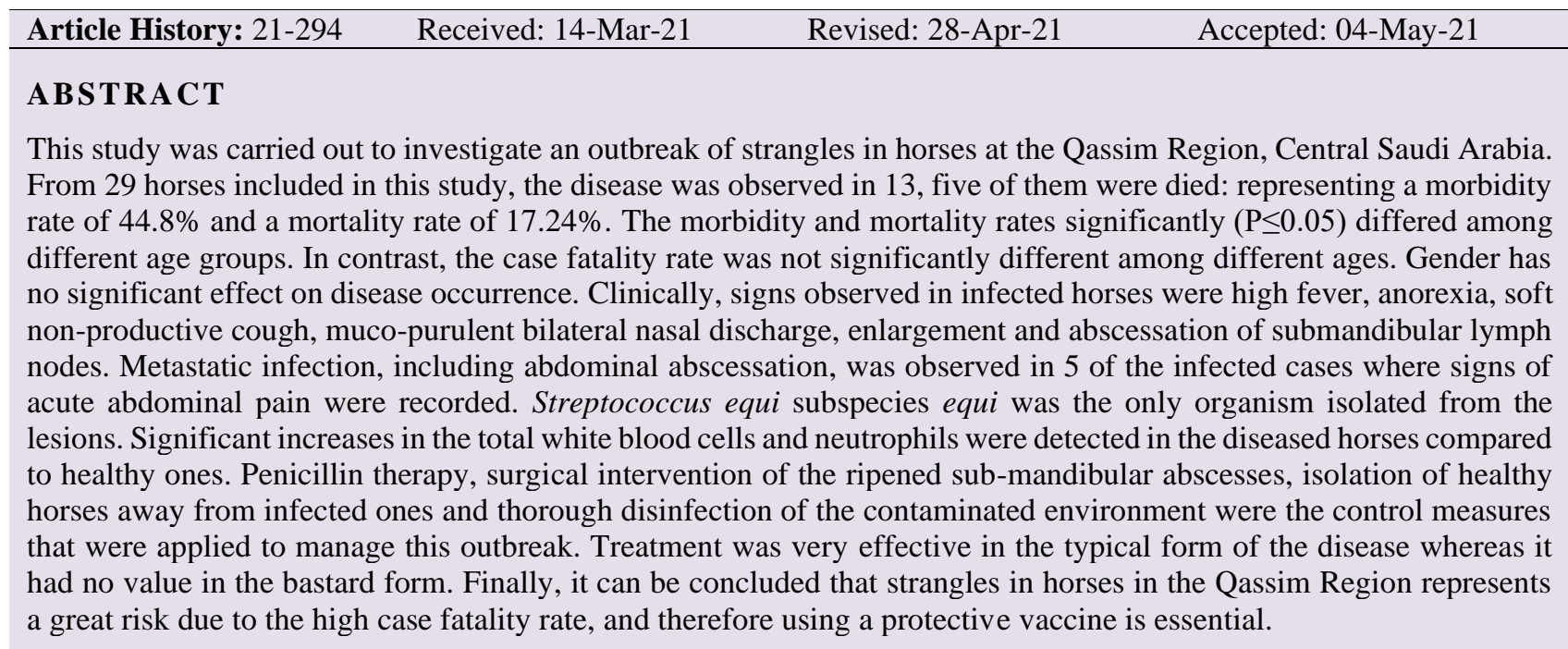

Key words: Strangles, Epidemiology, Streptococcus equi, Control.

C202I IJVS - All Rights Reserved

\section{INTRODUCTION}

Strangles is an acute and highly contagious bacterial disease affecting the respiratory system of equines, caused by Streptococcus equi subspecies equi (S. equi), a $\beta$ hemolytic, Lancefield's group $\mathrm{C}$ and mainly transmitted by direct contact with an infected horse or indirect contact with contaminated equipment (Lindah et al. 2011; Gharieb et al. 2019). The disease is endemic throughout the world causing considerable welfare and economic cost to the global horse industry (Robinson et al. 2018, 2020; Cohen et al. 2020). Equines can serve as carriers or reservoirs, therefore, are important for the maintenance of the bacteria between epizootics, making the control and prevention of the disease more difficult (Duran and Goehring 2021).

The disease has also been described in early veterinary science literature. It was first documented by Jordanus
Ruffus in 1251. The name strangles is due to the enlarged lymph nodes that made affected horses suffocate by obstructed airways (Sweeney et al. 2005; Liu et al. 2019).

Clinically, strangles is characterized by inflammation of the upper respiratory tract and abscessation in the adjacent lymph nodes. The infection starts in the pharyngeal and nasal passage resulting in the occurrence of pharyngitis and rhinitis (Boyle et al. 2018). Spread of the infection to the internal organs results in abscessation in the kidneys, brain, liver, spleen, tendon sheaths and joints. Strangles affects horses of different ages, but horses less than 5 years are particularly affected. Inhalation of infected droplets is the main route of infection followed by ingestion of contaminated foods. Complication as purpura hemorrhagica may happen as a result of the development of sensitivity to streptococcal protein (Noormohamad et al. 1992; Boyle et al. 2018; Ikhuoso et al. 2020). The morbidity rate

Cite This Article as: Osman SA, Tharwat M and Saeed EMA, 2021. An outbreak of strangles in arabian horses in Saudi Arabia: Epidemiology, clinical signs and treatment outcomes. International Journal of Veterinary Science 10(4): 323328. https://doi.org/10.47278/journal.ijvs/2021.061 
of the disease may reach up to $100 \%$, while the case fatality rate may not exceed $10 \%$ due to dissemination of the pus to the internal organs (Chanter et al. 2000).

Many predisposing risk factors such as overcrowding, mixing horses from different sources, breeding season, exposure to bad weather, concomitant disease, nutritional deficiency, and parasitic infestations are associated with strangles outbreaks (Oikawa et al. 1995; Moraes et al. 2009). Strangles is a common disease in Saudi Arabia where there is no vaccine available at present. This study describes an outbreak of strangles in Qassim Region, with especial reference to epidemiology, clinical signs, hematology and control measures applied during this outbreak.

\section{MATERIALS AND METHODS}

\section{Ethical Approval}

Ethical approval for this study was obtained from Animal Ethical Committee, Deanship for Scientific Research, Qassim University, Saudi Arabia.

\section{Animals}

Based on clinical signs suggestive of strangles, this study was conducted to investigate and manage an outbreak occurred in a private horse stable consisted of 29 Arabian horses of different ages and sexes in the Qassim Region, Central Saudi Arabia in 2019. During this outbreak, the number of horses showing clinical signs of strangles was 13,5 of them had died.

\section{Epidemiological Investigation}

Morbidity, mortality, and case fatality rates were estimated epidemiologically according to Martin et al. (1987). All horses in the infected stable were included in this study.

\section{Clinical Examination}

All horses under study were subjected to complete clinical examination, including temperature, pulse and respiratory rates, and examination of the mucous membranes according to the method described by Rosenberger (1979).

\section{Hematological Examination}

Two blood samples were collected via jugular vein puncture from the infected horses $(n=10)$ as well as from the apparently healthy ones $(n=10)$ in tubes containing ethylene diamine tetra acetic acid (EDTA) as an anticoagulant. Counts of white blood cell (WBC), neutrophil, lymphocyte, monocyte, eosinophil, basophil, and erythrocyte (EC), packed cell volume (PCV), and hemoglobin $(\mathrm{Hb})$ concentration were estimated using VetScan HM6, ABAXIS. These samples were taken before administration of any medications.

\section{Postmortem Examination}

During the postmortem examination, any gross abnormalities in the internal cavities and organs were recorded. Postmortem lesions were determined according to guidelines mentioned by FAO (2007).

\section{Bacteriological Examination}

Nasal swabs and pus samples were taken aseptically from infected horses and used for isolation of the causative agent. The samples were first enriched in brain heart infusion broth (HiMedia Laboratories, Mumbai, India) and then sub-cultured on 5\% sheep blood agar (Oxoid, Ltd, Basingstoke, UK). Inoculated media were incubated aerobically at $37^{\circ} \mathrm{C}$ for 48 hours (Forbes et al. 2007). Gramstained smears were prepared directly from samples and from broth and solid cultures and examined for presence of gram-positive cocci in short or long chains. Colony characteristics and catalase test result were recorded (Quinn et al. 2007). Identification of the obtained colonies was confirmed by VITEK 2 GP card (bioMérieux, Marcy L'E`toile, France).

\section{Control Measures}

Control of the outbreak was done through several steps including treatment of infected animals using Flunixin meglumin (Finadyne, MSD Animal Health) and penicillinstreptomycin (Pen \& Strep, NorBrook Co). Flunixin meglumin was administered by intravenous injection at a dose rate of $1 \mathrm{~mL}$ per $45 \mathrm{~kg}$ bodyweight (BW) $(1.1 \mathrm{mg}$ flunixin $/ \mathrm{kg}$ ) once daily for up to 5 days according to clinical response. Penicillin-streptomycin was administered by deep intramuscular once daily for 7 consecutive days at doses of $1 \mathrm{~mL} / 25 \mathrm{~kg} \mathrm{BW}$ (8mg procaine penicillin and $10 \mathrm{mg}$ dihydro-streptomycin sulphate $/ \mathrm{kg}$ $\mathrm{BW})$. Surgical intervention was done for the ripened abscesses plus irrigation using iodine in a separate place away from the farm, in addition to hygienic disposal of pus. Disinfection of the farm and equipment was done in adjunct with animal treatment. In contact healthy horses were isolated in a separate stable and injected with penicillinstreptomycin for five days. Moreover, avoiding contact between healthy and infected horses and overcrowding at water sources were considered to prevent the spread of the disease (Sweeney et al. 2005; Firew and Pal 2015).

\section{Statistical Analysis}

The obtained data was analyzed by chi-square and ttests using the SPSS for Windows (Version 15.0, USA) statistical software program, and probability (P-values) of less than 0.05 was considered significant.

\section{RESULTS}

Out of the examined 29 horses in this study, 13 horses showed typical signs of strangles representing a morbidity rate of $44.82 \%$. Out of these 13 horses, 5 were died representing a mortality rate of $17.24 \%$ and case fatality rate of $38.46 \%$ (Table 1 ). The morbidity rate was higher in young horses less than 5 years than those over 5 years. The morbidity and mortality rates in young horses were $72.72 \%$ and $36.36 \%$ compared to $27.27 \%$ and $5.55 \%$ in animals over 5 years. On the contrary, the case fatality rate was higher in young horses $(50 \%, 4 / 8)$ compared to adult ones $(20 \%, 1 / 5)$. Concerning sex predisposition, out of the examined 24 female and 5 male horses, 12 female and 1 male horse manifested the disease representing an infection rate of 50 and $20 \%$, respectively (Table 2).

Clinically, in this outbreak the infected horses showed two forms of the disease (typical and bastard). Signs observed were in the form of high fever, depression, anorexia, soft non-productive cough, muco-purulent bilateral nasal discharge, enlargement and abscessation of submandibular lymph nodes (Fig. 1). Blood examination 
Int J Vet Sci, 2021, 10(4): 323-328.

Table 1: Morbidity, mortality and case fatality rates during the strangles outbreak

\begin{tabular}{lcccccc}
\hline Age & Total Examined & Diseased & Dead & Morbidity $\%$ & Mortality $\%$ & Case fatality rate $(\%)$ \\
\hline Under 5 years & 11 & 8 & 4 & $72.72^{*}$ & $36.36^{*}$ & 50.00 \\
Over 5 years & 18 & 5 & 1 & 27.77 & 5.55 & 20.00 \\
Total & 29 & 13 & 5 & 44.82 & 17.24 & 38.46 \\
\hline
\end{tabular}

*Significant at $\mathrm{P}<0.05$ in a column.

Table 2: Prevalence of strangles in relation to sex in horses

\begin{tabular}{lccc}
\hline Sex & $\begin{array}{c}\text { Total camels } \\
\text { examined }\end{array}$ & $\begin{array}{c}\text { No. infected } \\
\text { camels }\end{array}$ & $\begin{array}{c}\text { Prevalence } \\
(\%)\end{array}$ \\
\hline Females & 24 & 12 & 50 \\
Males & 5 & 1 & 20 \\
Total & 29 & 13 & 44.2 \\
\hline
\end{tabular}

Table 3: Hemograms in healthy and horses infected with strangles $($ mean $\pm \mathrm{SD})$

\begin{tabular}{lcc}
\hline Variable & $\begin{array}{c}\text { Healthy horses } \\
(\mathrm{n}=10)\end{array}$ & $\begin{array}{c}\text { Infected horses } \\
(\mathrm{n}=10)\end{array}$ \\
\hline RBCs $\left(10^{6} / \mu \mathrm{l}\right)$ & $9.28 \pm 1.22$ & $8.94 \pm 1.13$ \\
$\mathrm{Hb}(\mathrm{g} / \mathrm{dl})$ & $13.71 \pm 2.12$ & $13.54 \pm 1.53$ \\
$\mathrm{PCV}(\%)$ & $37.93 \pm 6.06$ & $38.60 \pm 6.22$ \\
$\mathrm{WBCs}\left(10^{3} / \mu \mathrm{l}\right)$ & $7.92 \pm 2.66$ & $11.07 \pm 3.53^{*}$ \\
Neutrophils $\left(10^{3} / \mu \mathrm{l}\right)$ & $5.55 \pm 2.15$ & $8.29 \pm 2.95^{*}$ \\
Lymphocytes $\left(10^{3} / \mu \mathrm{l}\right)$ & $2.06 \pm 0.74$ & $2.00 \pm 0.77$ \\
Monocytes $\left(10^{3} / \mu \mathrm{l}\right)$ & $0.35 \pm 0.33$ & $0.39 \pm 0.32$ \\
Eosinophils $\left(10^{3} / \mu \mathrm{l}\right)$ & $0.17 \pm 0.10$ & $0.18 \pm 0.10$ \\
Platelets $\left(10^{9} / \mathrm{l}\right)$ & $255.20 \pm 109.06$ & $268.40 \pm 183.63$ \\
\hline
\end{tabular}

RBC, red blood cells; WBC, white blood cells; $\mathrm{Hb}$, hemoglobin concentration; $\mathrm{PCV}$, packed cell volume. *Significant at $\mathrm{P}<0.05$ in a row.

for infected animals revealed an increase in the white blood counts because of increase in the number of neutrophils (Table 3).

Metastatic infection including abdominal abscessation was observed in some of the infected cases. Two infected horses were died after severe colic for 12 hours. Necropsy findings revealed perforated mesenteric abscess that had led to severe peritonitis, peritoneal effusions, and intestinal adhesions. Postmortem lesions for one dead horse revealed perforated mesenteric abscess that had led to severe peritonitis, peritoneal effusions, and intestinal adhesions (Fig. 2).

Gram-stained smears revealed Gram-positive cocci arranged in short chains from the solid medium and long chains from the liquid medium and directly from the pus samples (Fig. 3a and b). On blood agar, beta-hemolytic small, circular, translucent, glistening, and mucoid colonies were observed, which were catalase-negative. Microscopic and colony characteristics were identical and consistent with Streptococcus equi. Isolates were confirmed by VITEK 2 as Streptococcus equi subspecies equi.

Results of the control measures that were applied to control this outbreak showed that the used treatment regimen was very effective in the typical form of the disease ( 8 cases were recovered) whereas it had no value in the bastard form ( 5 cases had died). Moreover, the applied control measures decreased the spread of the infection to other horses.

\section{DISCUSSION}

Strangles is considered as one of the most common bacterial disease in many countries. Epidemiologically, the disease is characterized by high morbidity and low mortality, resulting in great economic losses due to the expense of treatment, in addition to the restriction of horse movement (Islam et al. 2014; Boyle et al. 2018; Robinson et al. 2020; Duran and Goehring 2021). In the present outbreak, the morbidity rate among horses was $44.82 \%$, mortality rate was $17.24 \%$ and the case fatality rate was $38.46 \%$. Ford and Lokai (1980) recorded that the mortality rate of a typical form of strangles cannot exceed $2 \%$, while it can reach $62 \%$ in case of the bastard form.

Strangles is a highly infectious upper respiratory disease affecting horses of all ages, but most commonly in horses less than five years of age, especially in weanling foals or yearlings (Khoo et al. 2011; Tartor et al. 2020). The morbidity and mortality rates in this outbreak were significantly higher $(\mathrm{P} \leq 0.05)$ in young horses less than 5 years than those over 5 years. The morbidity and mortality rates in young horses were 72.72 and $36.36 \%$ compared to 27.27 and $5.55 \%$ in horses over 5 years. On the contrary, the case fatality rate was not significantly higher in young horses compared to adult ones. Similar observations were recorded previously by Manzoor et al. (2008) and Khoo et al. (2011). This may be attributed to the previous exposure of the adults to infection compared to the highly susceptible young horses (Boyle et al. 2018; Duran and Goehring 2021). Taylor and Wilson (2006) and Ijaz et al. (2012) mentioned that the disease was typically affected horses of all ages, but yearlings were mostly showed severe clinical signs.

Concerning sex predisposition, the morbidity rate did not differ significantly between male and female horses. Similar observation was recorded by Al-Gharban (2017), who observed that the prevalence of strangles among female horses was not significantly higher compared to males. This may be because of exposure of the male and female to the same risk.

Both typical and bastard forms of strangles were observed in this outbreak. Signs observed in the typical form were in the form of fever, depression, anorexia, respiratory dysfunction, in addition to enlargement and abscessation of submandibular lymph nodes, while signs of severe colic and deaths were observed in case of bastard form. Similar observations were recorded previously by Noormohamad et al. (1992), Boyle et al. (2018) and Ikhuoso et al. (2020).

According to Sweeney et al. (2005), the clinical signs of the bastard form of strangles differ according to the organ affected where aspiration of the purulent nasal discharges or hematogenous or lymphatic spread to the lung results in pneumonia, while abscessation of the mesentery, kidney, liver and spleen results in clinical signs of peritonitis and colic, while metastasis to the brain results in nervous manifestation.

Hematological findings for the healthy and strangles infected horses revealed significant increase in the white blood counts because of increase in the number of neutrophils in infected horses compared to healthy ones. 
Int J Vet Sci, 2021, 10(4): 323-328.

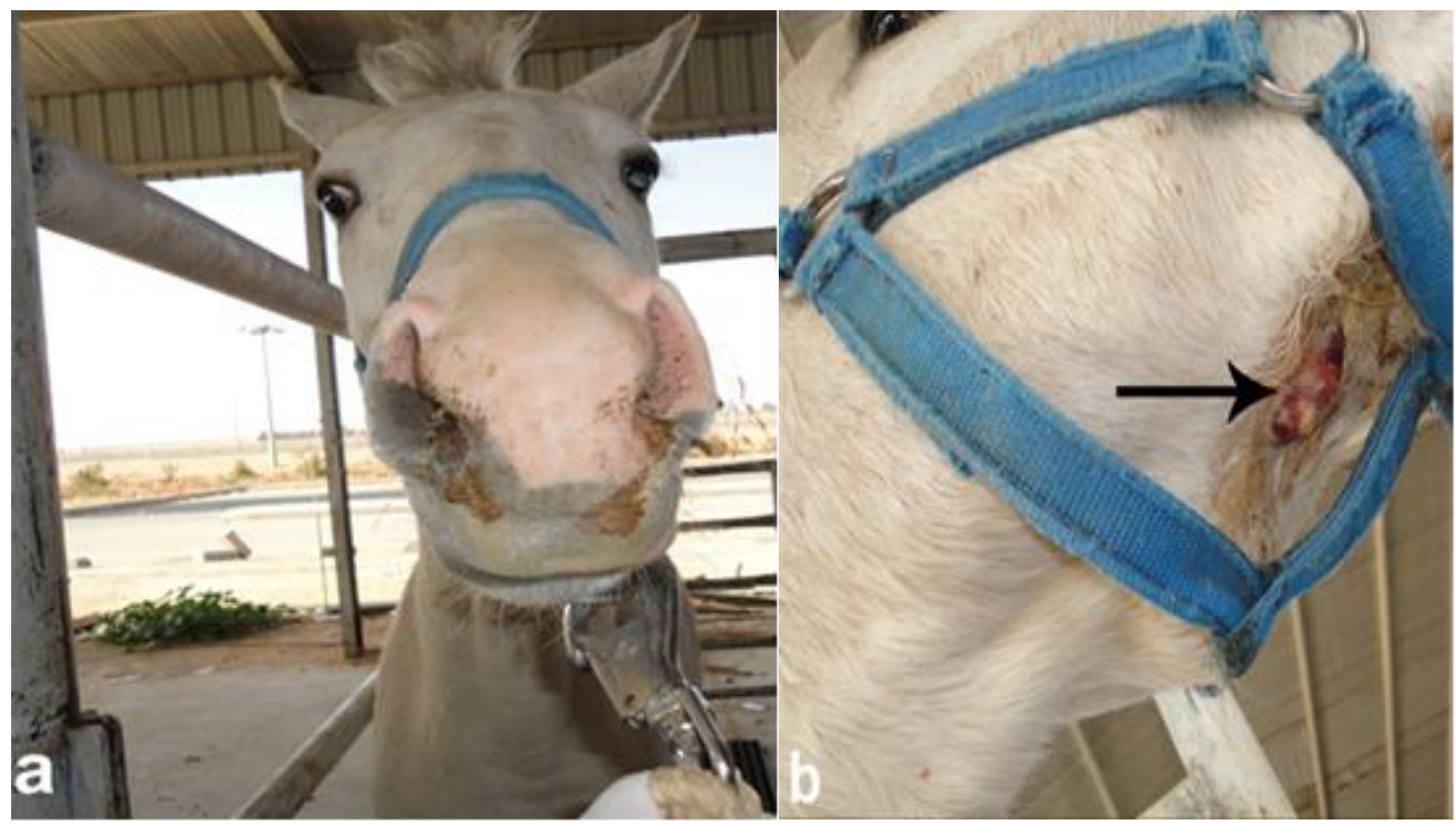

Fig. 1: Strangles-infected horse showing a) purulent nasal discharges and b) abscess in the submandibular lymph nodes.

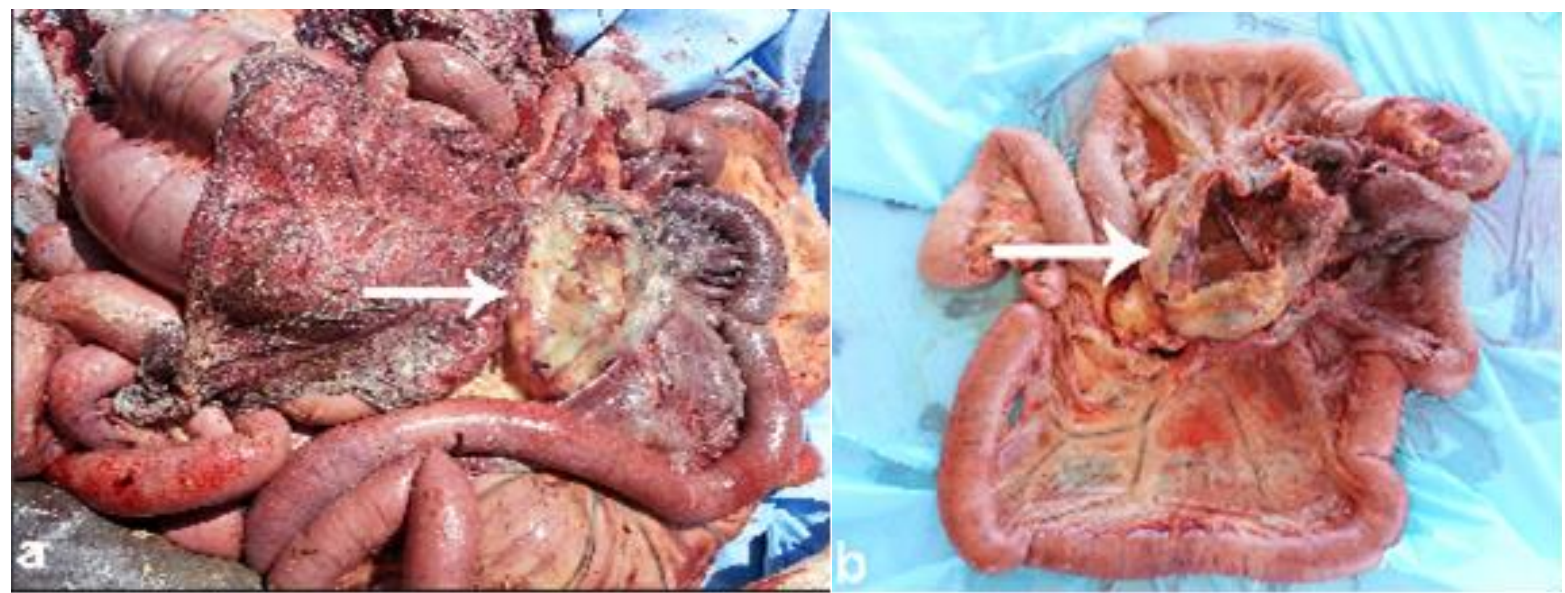

Fig. 2: Post-mortem finding in a horse with bastard form of strangles showing a) perforated mesenteric abscess and b) close-up view of the abscess.

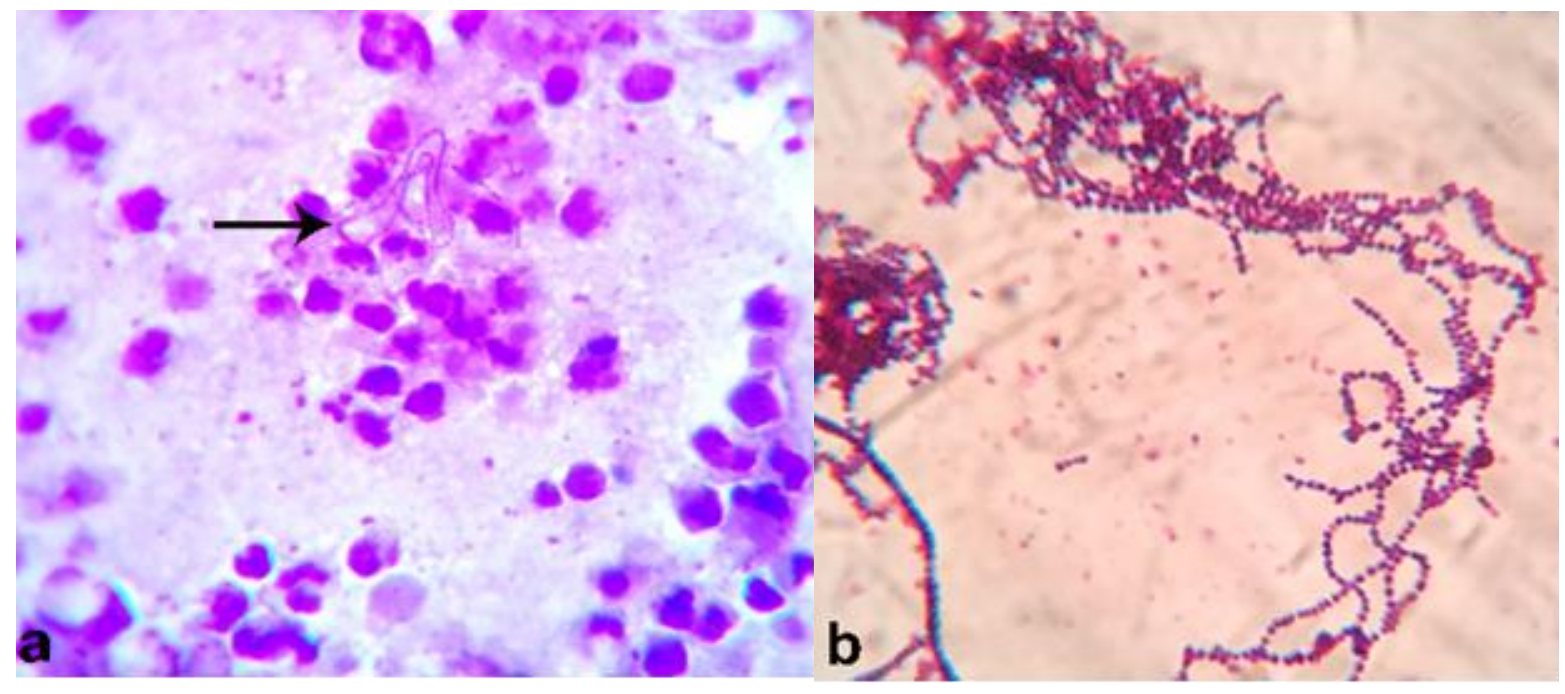

Fig. 3: Gram-stained smears showing Gram-positive cocci arranged in long chains (a) made directly from a pus sample, and (b) after enrichment in brain heart infusion broth medium. 
Similar findings were recorded previously by Timoney (1993) and Ijaz et al. (2011), who observed leukocytosis and a high-segmented neutrophil count in strangles infected equines.

After the occurrence of strangles outbreaks, Streptococcus equi persisted in clinically normal silent carriers for months to years (Pringle et al. 2019). So, treatment of infected horses must be done effectively to avoid development of these carriers. During this outbreak infected animals were treated using penicillinstreptomycin. Treatment was effective in the typical form of the disease whereas it had no value in the bastard form. Similar observation was recorded previously by Noormohamad et al. (1992), who reported that all strangles infected horses were responded effectively to the treatment with intramuscular injection of penicillin-streptomycin. Also, Manzoor et al. (2008) found that all of Streptococcus equi strains isolated from cases of strangles showed maximum sensitivity to penicillin and cefotoxime.

Other precautions were applied to minimize disease spread or environmental contamination in the form of hygienic disposal of the discharged pus, disinfection of the farm and equipment, avoiding contact between healthy and infected horses by isolation of healthy ones in a separate stable and preventing overcrowding at common water sources (Sweeney et al. 2005; Firew and Pal 2015; Duran and Goehring 2021). These control measures were found effective in decreasing the spread of the infection to other horses.

\section{Conclusion}

It is concluded that, strangles in horses in the Qassim Region, Saudi Arabia represents a great risk that can threat horse industry due to the high case fatality rate and therefore using a protective vaccine is essential in this region.

\section{Authors' Contribution}

All authors contributed equally to this work.

\section{REFERENCES}

Al-Gharban HAAJ, 2017. Seroepidemiological detection and culture utilization for diagnosis of carrier horses and donkeys with strangles. Journal of Education College Wasit University 1: 649-660. https://doi.org/10.31185/eduj. Vol1.Iss28.30.

Boyle AG, Timoney JF, Newton JR, Hines MT, Waller AS and Buchanan BR, 2018. Streptococcus equi infections in horses: Guidelines for treatment, control, and prevention of strangles-revised consensus statement. Journal of Veterinary Internal Medicine 32: 633-647. https://doi.org/10.1111/ jvim. 15043.

Chanter N, Nicola C, Talbot J, Newton R, Hewson D and Verheyen K, 2000. Streptococcus equi with truncated Mproteins isolated from outwardly healthy horses. Microbiology 146: 1361-1369. https://doi.org/10.1099/ 00221287-146-6-1361.

Cohen ND, Cywes-Bentley C, Kah SM, Bordi AI, Bray JM, Wehmeyer SG and Pier GB, 2020. Vaccination of yearling horses against poly-N-acetyl glucosamine fails to protect against infection with Streptococcus equi subspecies equi. PLoS One 15: e0240479. https://doi.org/10.1371/journal. pone.0240479.
Duran MC and Goehring LS, 2021. Equine strangles: An update on disease control and prevention. Australian Journal of Veterinary Sciences 53: 23-31. https://doi.org/10.4067/ S0719-81322021000100023.

FAO, 2007. Manual on meat inspection for developing countries. In: Animal Health and Production Papers, Food and Agriculture Organization of the United Nations pp: 27-31.

Firew S and Pal M, 2015. Clinical and microbiological observations on strangles in donkeys. Haryana Veterinarian 54: 64-66.

Forbes BA, Sahm DF, Weissfeld AS and Bailey WR, 2007. Bailey \& Scott's Diagnostic Microbiology, $12^{\text {th }}$ ed. Elsevier Mosby, Missouri, USA, pp: 216-217.

Ford J and Lokai MD, 1980. Complications of Streptococcus equi infection. Equine Practice 4: 41-44.

Gharieb NM, Ali WS, Tartor YH, EL-Naenaeey ESY and Ammar AM, 2019. Rapid and precise diagnostic tests for S. equi: An etiologic agent of equine strangles. Zagazig Veterinary Journal 47: 146-159. https://doi.org/10.21608/zvjz.2019. 9896.1024.

Ijaz M, Khan MS, Dourani AZ, Saleem MH, Chaudhry AS, Ali MM, Mehmood K and Shahzad W, 2012. Prevalence and biochemical studies of strangles (Streptococcus equi) affected horses in Pakistan. The Journal of Animal \& Plant Sciences 22: 295-229.

Ijaz M, Khan MS, Khan MA, Avais M, Ali MM and Saleem MH, 2011. Molecular identification and haematological values of strangles (Streptococcus equi) affected mules in Pakistan. Pakistan Journal of Zoology 43: 587-592.

Ikhuoso OA, Monroy JC, Rivas-Caceres RR, Cipriano-Salazar M and Pliego AB, 2020. Streptococcus equi in equine: Diagnostic and healthy performance impacts. Journal of Equine Veterinary Science 85: 102870. https://doi.org/ 10.1016/j.jevs.2019.102870.

Islam SMS, Purnat TD, Phuong NTA, Mwingira U, Schacht K and Fröschl G, 2014. Non-communicable diseases (NCDs) in developing countries: A symposium report. Globalization and Health 10: 81. https://doi.org/10.1186/s12992-0140081-9.

Khoo LL, Maswati MA, Roseliza R, Rosnah Y, Saifu Nazri R and Ramlan M, 2011. Isolation of Streptococcus equi during strangles surveillance in peninsular Malaysia. Malaysian Journal of Veterinary Research 2: 27 -32.

Lindah S, Söderlund R, Frosth S, Pringle J, Båverud V and Aspán A, 2011. Tracing out-breaks of Streptococcus equi infection (strangles) in horses using sequence variation in the SeM gene and pulse-field gel electrophoresis. Veterinary Microbiology 153: 144-149. https://doi.org/10.1016/j. vetmic.2011.03.027.

Liu Y, Gao N, He D, Waller A, Gu J, Wang T, Ji Y, Fan S, Yuan D, Du Y, Li F, Zhu W, Dong J and Han W, 2019. Identification of a novel genotype of Streptococcus equi subspecies equi in a donkey suffering from strangles. Pakistan Veterinary Journal 39: 609-611. http://doi.org/ 10.29261/pakvetj/2019.087

Manzoor S, Siddique M, Sajjad-ur-rahman R and Ashraf M, 2008. Occurrence of lancefield group c streptococcal species in strangles cases of foals in Punjab, Pakistan. Pakistan Veterinary Journal 28: 17-20.

Martin SW, Meek AH and Willeberg P, 1987. Veterinary Epidemiology: Principles and Methods. Iowa State University Press, Ames, Iowa, USA.

Moraes CM, Vargas APC, Leite FPL, Nogueira CEW and Turnes CG, 2009. Strangles: Etiology, diagnosis and control. Ciência Rural 39: 1944-1952. http://dx.doi.org/10.1590/ S0103-84782009000600050.

Noormohamad ZF, Abdullah PEG and Khajeh-Nasiri SM, 1992. Epizootiological investigation of strangles in the equine stables in Tehran. Journal of Equine Veterinary Science 12 401-402. https://doi.org/10.1016/S0737-0806(06)81370-5. 
Int J Vet Sci, 2021, 10(4): 323-328.

Oikawa M, Takagi S, Anzai R, Yoshikawa H and Yoshikawa T, 1995. Pathology of equine respiratory disease occurring in association with transport. Journal of Comparative Pathology 113: 29-43. https://doi.org/10.1016/S00219975(05)80066-0.

Pringle J, Venner M, Tscheschlok 1, Bächi L and Riihimäkia M, 2019. Long term silent carriers of Streptococcus equi ssp. equi following strangles; carrier detection related to sampling site of collection and culture versus qPCR. The Veterinary Journal 246: 66-70. https://doi.org/10.1016/j.tvjl. 2019.02.003.

Quinn PJ, Marky BK, Carter ME, Donnelly WJ and Leonard FC, 2007. Veterinary Microbiology and Infectious Diseases. Blackwell publishers, London, UK.

Robinson C, Frykberg L, Flock MM, Guss B, Waller AS and Flock JI, 2018. Strangvac: A recombinant fusion protein vaccine that protects against strangles, caused by Streptococcus equi. Vaccine 36: 1484-1490. https://doi.org/ 10.1016/j.vaccine.2018.01.030.

Robinson C, Waller AS, Frykberg L, Flock M, Zachrisson O, Guss B and Flock JJ, 2020. Intramuscular vaccination with
Strangvac is safe and induces protection against equine strangles caused by Streptococcus equi. Vaccine 38: 48614868. https://doi.org/10.1016/j.vaccine.2020.05.046.

Rosenberger G, 1979. Clinical Examination of Cattle. A Text Book, $3^{\text {rd }}$ Ed. Praey, Berlin, Germany.

Sweeney CR, Timoney JF, Newton JR and Hines MT, 2005. Streptococcus equi infections in horses: Guidelines for treatment, control and prevention of strangles. Journal of Veterinary Internal Medicine 19:123-134.

Tartor YH, EL-Naenaeey EY, Gharieb NM, Ali WS and Ammar AM, 2020. Novel Streptococcus equi strains causing strangles outbreaks in Arabian horses in Egypt. Transboundary and Emerging Diseases 67: 2455-2466. https://doi.org/10.1111/tbed.13584.

Taylor SD and Wilson WD, 2006. Streptococcus equi subsp. equi (strangles) infection. Clinical Techniques in Equine Practice 5: 211-217. https://doi.org/10.1053/j.ctep.2006.03.016

Timoney JF, 1993. Strangles. Veterinary clinics of North America. Equine Practice 9: 365-373. https://doi.org/ 10.1016/s0749-0739(17)30403-0. 